Correction

\title{
Correction: HOTAIR regulates HK2 expression by binding endogenous miR-125 and miR-143 in oesophageal squamous cell carcinoma progression
}

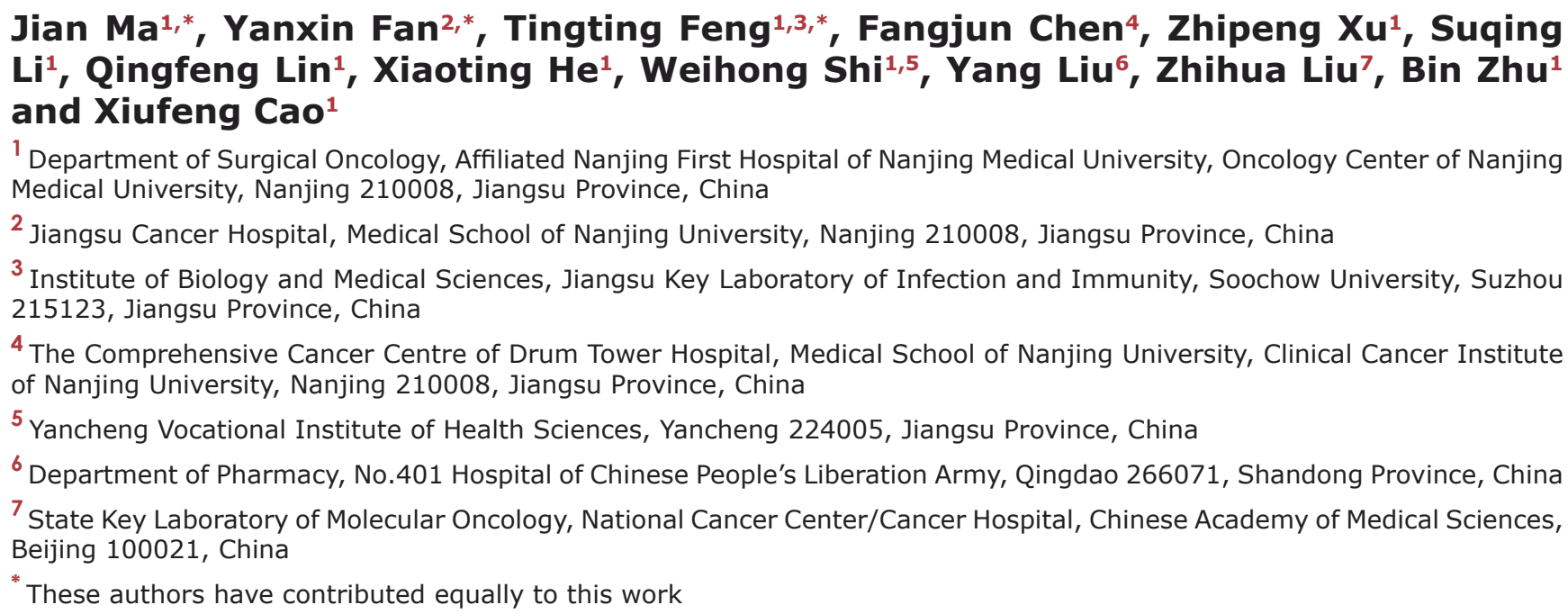

Copyright: Ma et al. This is an open-access article distributed under the terms of the Creative Commons Attribution License 3.0 (CC BY 3.0), which permits unrestricted use, distribution, and reproduction in any medium, provided the original author and source are credited.

This article has been corrected: The correct order of Author names are given below:

\section{Jian $\mathrm{Ma}^{1, *}$, Yanxin Fan ${ }^{2, *}$, Tingting Feng ${ }^{1,3, *}$, Fangjun Chen ${ }^{4}$, Zhipeng $\mathrm{Xu}^{1}{ }^{1}$, Suqing $\mathrm{Li}^{1}$, Qingfeng Lin ${ }^{1}$, Xiaoting $\mathrm{He}^{1}$, Weihong Shi, ${ }^{1,5}$, Yang Liu ${ }^{6}$, Zhihua Liu ${ }^{7}$, Bin Zhu ${ }^{1}$ and Xiufeng $\mathrm{CaO}^{1}$}

Original article: Oncotarget. 2017; 8:86410-86422. https://doi.org/10.18632/oncotarget.21195 